\title{
Blowflies as vectors of Bacillus anthracis in the Kruger National Park
}

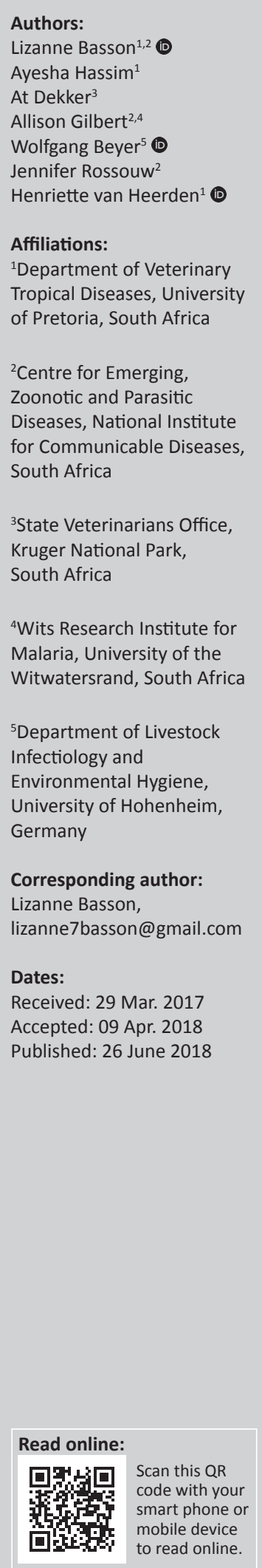

Anthrax, caused by Bacillus anthracis, is endemic in the Kruger National Park (KNP). The epidemiology of $B$. anthracis is dependent on various factors including vectors.

The aims of this study were to examine non-biting blowflies for the presence of $B$. anthracis externally and internally after feeding on an anthrax-infected carcass and to determine the role of flies in disseminating B. anthracis onto the surrounding vegetation.

During an anthrax outbreak in 2014 in the endemic Pafuri region, blowflies associated with two 2-3-day-old anthrax-positive carcasses (kudu and impala) as well as surrounding vegetation were collected and investigated for the presence of $B$. anthracis spores.

The non-biting blowflies $(n=57)$ caught included Chrysomya albiceps, Ch. marginalis and Lucilia spp. Bacillus anthracis spores were isolated from $65.5 \%$ and $25.0 \%$ of blowflies collected from the kudu and impala carcasses, respectively.

Chrysomya albiceps and Ch. marginalis have the potential to disseminate B. anthracis to vegetation from infected carcasses and may play a role in the epidemiology of anthrax in the KNP. No B. anthracis spores were initially isolated from leaves of the surrounding vegetation using selective media. However, 170 and 500 spores were subsequently isolated from Abutilon angulatum and Acacia sp. leaves, respectively, when using sheep blood agar.

Conservation implications: The results obtained in this study have no direct conservation implications and only assist in the understanding of the spread of the disease.

\section{Introduction}

Anthrax is a serious zoonotic disease affecting mainly herbivores. It is caused by the soil-borne, Gram-positive, spore-forming organism Bacillus anthracis. In unfavourable conditions, B. anthracis forms endospores that can remain dormant in the environment for long periods of time surviving outside the host. The spores are ingested by a susceptible host, where germination and multiplication occur in vivo. The host dies and the carcass is opened by scavengers or human, resulting in the vegetative cells being exposed to oxygen and sporulating; remaining in the soil until another host ingests the spores and the cycle is repeated (Dragon \& Rennie 1995). Anthrax occurs endemically in the northern Kruger National Park (KNP) and the Northern Cape Province (Ghaap plateau area) in South Africa (Hugh-Jones \& De Vos 2002). The disease cannot spread from one living animal to the next; therefore, the life cycle is dependent on various factors including rainfall, temperature, type of soil, animal densities and the presence of susceptible hosts (Dragon \& Rennie 1995).

A number of abiotic and biotic vectors such as insects (biting flies, blowflies, mosquitoes and ticks) (Blackburn et al. 2010; Fasanella et al. 2010; Graham-Smith 1913; Turell \& Knudson 1987), scavengers (Pienaar 1961, 1967), soil (Hugh-Jones \& Blackburn 2009) and water (Hugh-Jones \& De Vos 2002; Pienaar 1961) have also been implicated in the dissemination of anthrax. The main insect vectors implicated with anthrax in the KNP are the blowflies Chrysomya albiceps and Ch. marginalis (Braack 1985) as these species are the first (and most abundant) insects to arrive shortly after death. These two species consume infected bodily fluids and are probably the principal vectors in the dissemination of B. anthracis (Braack 1985; Braack \& Retief 1986). Chrysomya albiceps and Ch. marginalis have been hypothesised to spread the bacteria over short distances despite the fact that blowflies have the ability to travel great distances $(35 \mathrm{~km}-65 \mathrm{~km})$.

How to cite this article: Basson, L., Hassim, A., Dekker, A., Gilbert, A., Beyer, W., Rossouw, J. \& Van Heerden, H., 2018, 'Blowflies as vectors of Bacillus anthracis in the Kruger National Park', Koedoe 60(1), a1468. https://doi.org/10.4102/koedoe.v60i1.1468

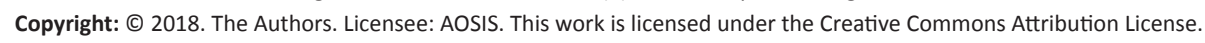


They normally rest on nearby vegetation when engorged and deposit most of the contaminated defaecation and/or vomit droplets close to the carcass (Braack \& De Vos 1990; De Vos 1990) of vegetation (reviewed by De Vos 1994), which pose a risk of infection to susceptible herbivores.

In KNP, outbreaks were usually associated with the driest periods of the year (winter and early spring) or during climatic dry cycles (Pienaar 1967). However, since the 2010 outbreak onwards, outbreaks mainly occurred in wet periods (summer months; E.H. Dekker [Skukuza State Veterinary Office] pers. comm., 2014). This is of importance as insect activity and abundance on a carcass is influenced by climate. In the rainy season, the insect abundance (especially the blowflies) will increase, which was speculated by Braack (1985) to increase B. anthracis dissemination by blowflies to vegetation during an outbreak. Scavengers have also been speculated to disseminate spores at drinking holes after opening and feeding on anthrax-infected carcasses (Pienaar 1961). Research conducted by Turner et al. $(2014,2016)$ indicated that grazing seems to play a significant role in the dissemination of B. anthracis in Etosha National Park. Similar investigations must be performed in KNP to determine the factors influencing the epidemiology of anthrax as well as the amount of spores found on flies and the bacterial load defaecated or regurgitated by flies on vegetation.

In this study, we investigated the possible role of blowflies in carrying and/or spreading B. anthracis during an anthrax outbreak in the KNP. This aim was investigated by quantifying the presence of B. anthracis on the exterior and interior of blowflies after feeding on an anthrax-contaminated carcass. Furthermore, the role of blowflies in the dissemination of $B$. anthracis onto the surrounding vegetation during the anthrax outbreak in the KNP was also investigated.

\section{Materials and methods Blowfly collection and identification}

In March 2014 - April 2014, blowflies were collected from two confirmed anthrax-positive carcasses (a kudu and an impala) during an anthrax outbreak in the endemic Pafuri region of the KNP. The adult male kudu carcass was approximately 2-3 days old, lying in the open with clear indications that scavengers (vultures and/or hyenas) had started to feed on it. The adult male impala carcass infected with anthrax was about three days old, lying under a low thorn tree (Acacia sp.). The carcass was mostly intact, except for a large opening in the abdomen region. A net trap was used to collect the blowflies on the carcass. Trapped flies were collected and placed in liquid nitrogen for 30 seconds and transported at $4{ }^{\circ} \mathrm{C}$ to the National Institute for Communicable Diseases (NICD) for further bacteriological analysis. All blowflies were kept, while other flies were discarded. Each blowfly was identified and sexed using the identification method described by Zumpt (1965). Blowflies that were not phenotypically or morphologically distinguishable were identified by sequencing of the ribosomal DNA internally transcribed spacer 2 (ITS 2) region that differentiates Calliphoridae as described by Koekemoer et al. (2002).

\section{Isolation of Bacillus anthracis from blowflies}

Each blowfly was tested for the presence of $B$. anthracis vegetative cells and spores on the interior and exterior surfaces. To detect the presence of $B$. anthracis on exterior surfaces, each blowfly was washed in $1 \mathrm{~mL}$ sterile saline to remove any bacteria. The presence of $B$. anthracis vegetative cells was determined by plating 10 -fold dilutions $\left(10^{0}-10^{8}\right)$ from the external wash onto polymyxin-EDTA-thallium acetate (PET; modified polymyxin-lysozyme-EDTA-thallium acetate [PLET] where lysozyme was omitted) agar plates followed by incubation at $37^{\circ} \mathrm{C}$ for 48 hours. The presence of B. anthracis spores was determined by plating $100 \mu \mathrm{L}$ heattreated $\left(62.5^{\circ} \mathrm{C}\right.$ for $\left.15 \mathrm{~min}\right)$ undiluted external wash on PET agar, followed by incubation at $37^{\circ} \mathrm{C}$ for $48 \mathrm{~h}$.

After the exterior wash step, each blowfly was disinfected with $1 \mathrm{~mL} 0.1 \%(\mathrm{v} / \mathrm{v})$ peracetic acid for $1 \mathrm{~h}$ to inactivate any residual bacteria left over on the exterior of the blowfly after the wash step. The $0.1 \%$ peracetic acid $(\mathrm{v} / \mathrm{v})$ was neutralised by $1 \mathrm{~mL} 0.8 \%$ sodium bicarbonate - sodium chloride $(\mathrm{v} / \mathrm{v})$ solution for $1 \mathrm{~h}$. One-hundred microliters of the neutralised external wash was inoculated onto $5 \%$ sheep blood agar (SBA) and incubated at $37{ }^{\circ} \mathrm{C}$ for $24 \mathrm{~h}$ to ensure that no bacteria were present on exterior surface of the blowflies.

The presence of internal (ingested) B. anthracis was determined by homogenising each blowfly in $1 \mathrm{~mL}$ saline. The homogenised blowfly was briefly centrifuged $(500 \times g$ for $5 \mathrm{~s})$ to separate the blowfly debris from the supernatant. Tenfold serial dilutions $\left(10^{0}-10^{8}\right)$ of the supernatant were prepared and plated on PET agar and incubated at $37^{\circ} \mathrm{C}$ for $48 \mathrm{~h}$. The presence of $B$. anthracis spores was determined by plating $100 \mu \mathrm{L}$ heat-treated undiluted supernatant onto PET followed by incubation at $37^{\circ} \mathrm{C}$ for $48 \mathrm{~h}$.

\section{Isolation of Bacillus anthracis from vegetation}

Leaves from shrubs with blowfly defaecation or discard droplets around the infected carcasses were collected and transported at $4{ }^{\circ} \mathrm{C}$ to the NICD. Each defaecation or discard droplet was removed from the leaves by using a transport swab pre-wetted with saline, followed by the swabs being rinsed in $1 \mathrm{~mL}$ sterile water. Bacillus anthracis was detected by plating $100 \mu \mathrm{L}$ undiluted wash before and after heat treatment on PET and SBA plates followed by incubation at $37^{\circ} \mathrm{C}$ for 48 h. Leaves without any defaecation or discard droplets were sent to Prof. K. Eloff at the University of Pretoria for identification and to determine antibacterial activity. The minimum inhibitory concentration (MIC in $\mathrm{mg} / \mathrm{mL}$ ) of acetone extracts of the plant was tested against five bacterial organisms (Escherichia coli, Enterococcus faecalis, Pseudomonas aeruginosa, Staphylococcus aureus and B. anthracis Sterne) using the protocol as previously described by Eloff (1998). 


\section{Confirmation of Bacillus anthracis}

Bacillus anthracis isolates were identified based on the characteristic colony morphology (ground glass appearance, fairly flat, more tacky and white or grey-white), no haemolytic activity, penicillin sensitivity and gamma phage sensitivity after $24 \mathrm{~h}$ incubation at $37{ }^{\circ} \mathrm{C}$ on $5 \%$ SBA as described by World Health Organization (2008). Each confirmed B. anthracis colony of vegetative cell and spores was counted and recorded, followed by the calculation of total colony forming units per fly (CFU/fly).

\section{Results}

The two carcasses were confirmed to be anthrax-positive through the presence of bacilli and endospores in a Giemsastained blood smear as well as through the isolation of B. anthracis through culture. Twenty-nine blowflies were collected from the kudu carcass and 28 blowflies from the impala carcass (Table 1). Chrysomya marginalis, Ch. albiceps and Lucilia spp. females were collected from the kudu carcass (with a female:male ratio of 3:1), whereas only Ch. marginalis males and females were collected from the impala carcass (female:male ratio of 2:5) (Table 1).

Only B. anthracis spores were isolated from the blowflies. A total of $26(46 \% ; 26 / 57)$ blowflies were positive for the presence of $B$. anthracis spores, with $66 \%(19 / 29)$ of blowflies collected from the kudu carcass and $25 \%(7 / 28)$ of the blowflies collected from the impala carcass (Table 2). The Ch. marginalis blowflies collected from the kudu carcass had an average internal and external spore count of 128 CFU/fly. The Ch. albiceps blowfly collected from the kudu carcass was only positive on the interior with $20 \mathrm{CFU} /$ fly. A low B. anthracis spore count of $10 \mathrm{CFU} /$ fly was isolated from the exterior of the two Lucilia spp. (Appendix 1). The Ch. marginalis blowflies collected from the male impala

TABLE 1: Summary of blowfly species collected from two anthrax carcasses during an anthrax outbreak in March 2014 in the Kruger National Park.

\begin{tabular}{|c|c|c|c|c|c|}
\hline \multirow[t]{2}{*}{ Fly species } & \multirow[t]{2}{*}{ Sex } & \multicolumn{2}{|c|}{ Kudu carcass } & \multicolumn{2}{|c|}{ Impala carcass } \\
\hline & & $\%$ & $\begin{array}{l}\text { Total number } \\
\text { positive out of } \\
\text { total collected }\end{array}$ & $\%$ & $\begin{array}{l}\text { Total number } \\
\text { positive out of } \\
\text { total collected }\end{array}$ \\
\hline \multirow{2}{*}{$\begin{array}{l}\text { Chrysomya } \\
\text { albiceps }\end{array}$} & Female & 10.4 & $3 / 29$ & - & - \\
\hline & Male & - & - & - & - \\
\hline \multirow{2}{*}{$\begin{array}{l}\text { Chrysomya } \\
\text { marginalis }\end{array}$} & Female & 48.3 & $14 / 29$ & 28.6 & $8 / 28$ \\
\hline & Male & 24.1 & $7 / 29$ & 71.4 & $20 / 28$ \\
\hline \multirow[t]{2}{*}{ Lucilia spp. } & Female & 17.2 & $5 / 29$ & - & - \\
\hline & Male & - & - & - & - \\
\hline
\end{tabular}

carcass had an average internal and external spore count of $26 \mathrm{CFU} /$ fly (Appendix 2).

The shrub where blowflies defaecated or regurgitated after feeding on infected carcasses was identified as Abutilon angulatum approximately $2.5 \mathrm{~m}$ from the kudu carcass and leaves were collected with blowfly defaecation or regurgitation spots. An average of ten defaecation or regurgitation spots was found per A. angulatum leaf. No $B$. anthracis was isolated from the A. angulatum shrub leaves using selective medium combined with or without heat treatment, but 170 spores were isolated from one defaecation or regurgitation spot cultured on 5\% SBA with no heat treatment. From a single thorny stem of an Acacia tree, 500 spores per droplet for three out of eight defaecation or regurgitation spots were isolated on 5\% SBA without heat treatment. Because of the absence of spores on non-selective medium, the antimicrobial activity of the A. angulatum shrub was tested and the results indicated that the MIC of the A. angulatum acetone extract was most effective against E. coli $(0.08 \mathrm{mg} / \mathrm{mL})$ and had a moderate inhibitory effect towards E. faecalis, S. aureus and B. anthracis (Sterne) with $0.31 \mathrm{mg} / \mathrm{mL}$.

\section{Discussion}

Chrysomya albiceps, Ch. marginalis and Lucilia spp. were collected from two B. anthracis carcasses and their abundance confirms that these carcasses were $2-3$ days old as indicated by the investigation of carcass-attending insect communities in the KNP of Braack (1985). Chrysomya marginalis usually arrives within a couple of minutes to hours after death of animals and stays at a carcass for approximately 4 days, whereas Ch. albiceps arrives a couple of hours after the death and remains at a carcass for about 3 days in the KNP (Braack 1985). Lucilia spp. usually arrives at the same time as Ch. marginalis, but in far less numbers. The major blowfly species collected from anthrax-infected carcasses was Ch. marginalis of which $88 \%$ was B. anthracis culture-positive. No viable $B$. anthracis was isolated from any of the vegetation using selective media and could only be isolated using SBA. Based on the culture results using selective (PET) and enrichment (SBA) media, it seems that the selective medium has an inhibitory effect on $B$. anthracis spore germination from leaves, which was not the case with germination from the blowflies themselves. Because of initial negative results of the selective media from the $A$. angulatum leaves, we tested for antibacterial activity and found a moderate inhibitory effect on the non-virulent Sterne strain of B. anthracis by phytocompounds within A. angulatum.

TABLE 2: Blowflies positive for Bacillus anthracis spores collected from the confirmed anthrax kudu and impala carcasses during an anthrax outbreak in the Kruger National Park in March 2014.

\begin{tabular}{|c|c|c|c|c|c|c|c|c|}
\hline \multirow[t]{2}{*}{ Variable } & \multicolumn{2}{|c|}{ Only internal positive } & \multicolumn{2}{|c|}{ Only external positive } & \multicolumn{2}{|c|}{ Internal and external positive } & \multicolumn{2}{|c|}{ Negative } \\
\hline & $\%$ & $\begin{array}{l}\text { Total number } \\
\text { positive out of } \\
\text { total collected }\end{array}$ & $\%$ & $\begin{array}{l}\text { Total number } \\
\text { positive out of } \\
\text { total collected }\end{array}$ & $\%$ & $\begin{array}{l}\text { Total number } \\
\text { positive out of } \\
\text { total collected }\end{array}$ & $\%$ & $\begin{array}{l}\text { Total number } \\
\text { positive out of } \\
\text { total collected }\end{array}$ \\
\hline Kudu carcass $(n=29)$ & 10.40 & $3 / 29$ & 17.20 & $5 / 29$ & 37.90 & $11 / 29$ & 34.50 & $10 / 29$ \\
\hline Impala carcass $(n=28)$ & 17.90 & $5 / 28$ & 7.10 & $2 / 28$ & 0.00 & - & 75.00 & $21 / 28$ \\
\hline Total $(n=57)$ & 14.00 & $8 / 57$ & 12.30 & $7 / 57$ & 19.30 & $11 / 57$ & 54.40 & $31 / 57$ \\
\hline
\end{tabular}


Only spores, and no vegetative organisms, from B. anthracis were isolated from the interior and exterior of blowflies, which could be attributed to various factors that could have killed the more labile vegetative organisms. These factors include the freezing of the flies in liquid nitrogen, collection time and the period between collection and processing of the flies. Graham-Smith (1913) fed Musca domestica and Calliphora erythrocephala on $B$. anthracis vegetative cells and spores and recovered only $B$. anthracis spores for up to ten days from fly legs and wings and seven days from both the gut and the crop. Vegetative cells were present on legs and wings for up to $24 \mathrm{~h}$, lending further evidence to our findings. In this study, the collected flies were frozen in liquid nitrogen. Haines (1938) found that $90 \%$ B. mesentericus spores were viable after $-70{ }^{\circ} \mathrm{C}$ freezing with varying loss of viability of the vegetative cells and Young et al. (1968) suggested that vegetative cells of spore-forming bacteria are more susceptible to damage from freeze-thawing than vegetative cells of nonspore-forming bacteria. Therefore, it is presumed that the freezing of the flies in liquid nitrogen did not influence the spore count significantly, as we only found spores. The absence of vegetative cells could be because of the use of liquid nitrogen to kill the blowflies.

Various researchers have determined that flies can potentially transmit $B$. anthracis to their surroundings and that these flies are carriers of the bacteria for numerous days (Blackburn et al. 2010, 2014; Hugh-Jones \& Blackburn 2009; Von Terzi et al. 2014). According to De Vos (1990), explosions of blowfly populations preceded the anthrax outbreaks in the KNP in 1960 and 1970. Blackburn et al. (2010) speculated that blowflies and flesh flies are responsible for the spread of an anthrax outbreak in white-tailed deer in the USA, which was later confirmed by isolating $B$. anthracis DNA from leaves collected 21 days post-outbreak as well as viable B. anthracis from blowfly larvae and one adult that can potentially infect the surrounding vegetation (Blackburn et al. 2014). This coincides with the findings of this study where B. anthracis could not be isolated from leaves using selective medium. This could explain why only B. anthracis DNA on leaves was detected by Blackburn et al. (2014). The suppressive nature of selective media on $B$. anthracis from environmental samples needs further investigation.

Two recent studies investigated fly species as potential mechanical or biological vectors of $B$. anthracis. Fasanella et al. (2010) allowed the common housefly (M. domestica) to feed on B. anthracis-infected rabbit carcasses or B. anthraciscontaminated blood and indicated the presence of $B$. anthracis spores in defaecation or vomit spots as well as hypothesised that anthrax spores are able to germinate and replicate in the gut content of $M$. domestica. These authors hypothesise that the housefly has the potential to act as a biological vector for B. anthracis. Von Terzi et al. (2014) demonstrated that B. anthracis vegetative cells are unable to multiply inside the gut of Calliphora vicina and cannot survive for longer than a week. These authors' results show high numbers of viable B. anthracis indicating the role of C. vicina as only mechanical vectors as previously hypothesised (Blackburn et al. 2010; Hugh-Jones \& Blackburn 2009; Hugh-Jones \& De Vos 2002).

The Ch. albiceps had less spores per fly (20 CFU / fly) compared to Ch. marginalis (128 CFU/fly) collected at the kudu carcass. Only Ch. marginalis was caught at the impala carcass with 25 CFU/fly. The reason for the larger spore count present on flies at the kudu carcass could be attributed to the bacterial load of the host, or more sporulation as the kudu carcass was opened by scavengers compared to the partially opened impala carcass that might have been protected from scavengers by the Acacia shrub. The total CFUs isolated per fly reflect the potential infectious load of a fly with an average of 87 B. anthracis CFU/fly depending on the blowfly species. It is not known how many spores were defaecated onto the surrounding vegetation by flies, but 170 spores were isolated from a defaecated spot on the $A$. angulatum leave. Our results show that $B$. anthracis is present in and on blowflies that actively fed on an anthrax carcass and that the faecal or discard droplets left on leaves are infective. This can then lead to the assumption that blowflies can aid in the dissemination of $B$. anthracis to susceptible host species.

As anthrax carcass sites are the primary sources for future infections (Turner et al. 2014, 2016), it will depend if the spore doses from surrounding infected vegetation are lethal. Considering the 170-500 spores per leaf or twig (that weighed approximately $1 \mathrm{~g}-2 \mathrm{~g}$ ) found in this study, a lethal dose of around $10^{5}-10^{7}$ for gastrointestinal anthrax (Turner et al. 2016) can easily be ingested during anthrax outbreaks as impala ingests $0.9 \mathrm{~kg}-1.9 \mathrm{~kg}$ per day (Furstenburg 2002) and kudu $3.7 \mathrm{~kg}-5.0 \mathrm{~kg}$ per day (http:/ / www.wildliferanching.com/content/kudu-tragelaphusstrepsiceros). However, because of the small sample size (host species and blowflies), further research is necessary to investigate the spore load present in the different host species and CFU on and defaecated by the different blowfly species.

Despite the unique findings of this study, specifically in the KNP, it only involved two carcasses of different species with blowflies being collected at one specific time point. To obtain a clearer view of the infectious load of blowflies feeding on a carcass under different climatic conditions, a temporal study over a longer time period should be conducted. Ideally, blowflies should be collected daily from carcasses and the surrounding vegetation until the carcasses are completely decomposed giving insights into the extent of the role that blowflies may play in anthrax transmission. While most studies indicate that blowflies play a role as a vector of B. anthracis, the epidemiological significance of this role is difficult to determine because various factors need to be considered, including the survival of the spores on or in blowflies, the spore load in defaecation or vomit spots of blowflies, and hence, on the vegetation, the latter depending on climatic conditions and antimicrobial activity of the plant(s), and last but not least the effective dose required by susceptible host species. 


\section{Conclusion}

In conclusion, the results obtained from this study indicate that blowflies feeding on an anthrax-contaminated carcass can contaminate surrounding vegetation and aid in the continuous cycle of $B$. anthracis. If there are high numbers of blowflies feeding on a carcass, it can lead to high bacillus or spore numbers being deposited on the surrounding vegetation. This can then lead to a new infection of a susceptible host through the ingestion of contaminated vegetation.

\section{Acknowledgements}

This research was funded by the National Research Foundation, Deutsche Forschungsgemeinschaft and Agricultural Sector Education and Training Authority (AgriSETA). The authors would like to acknowledge SANParks for approving this research in the Kruger National Park and Skukuza State Veterinary Services, Department of Agriculture, Forestry and Fisheries for support during collection.

\section{Competing interests}

The authors declare that they have no financial or personal relationships that may have inappropriately influenced them in writing this article.

\section{Authors' contributions}

L.B. did the experiments and wrote the manuscript. Knowledge transfer of techniques to L.B. used in this study was done by A.H., A.D. and A.G. A.H. did most of the vegetation experiments. A.G. was responsible for the polymerase chain reaction (PCR) identification of the blowflies. W.B., J.R. and H.V.H. participated in the design of the study and cosupervised the first author. W.B. has been the principal investigator of the DFG project BE2157/4-1. H.v.H. and W.B. were provided funding through AgriSETA and the Deutsche Forschungsgemeinschaft, respectively. L.B. received a National Research Foundation (NRF) Freestanding Innovation Scholarship. All authors participated in critical revision of the manuscript.

\section{References}

Blackburn, J.K., Curtis, A., Hadfield, T.L., O'Shea, B., Mitchell, M.A. \& Hugh-Jones, M., 2010, 'Confirmation of Bacillus anthracis from flesh-eating flies collected during a west Texas anthrax season', Journal of Wildlife Diseases 46, 918-922. https://doi. org/10.7589/0090-3558-46.3.918
Blackburn, J.K., Mullins, J.C., Van Ert, M., Hadfield, T.L., O'Shea, B. \& Hugh-Jones, M., 2014, 'The necrophagous fly anthrax transmission pathway: Empirical and genetic evidence from a wildlife epizootic in West Texas 2010', Vector-Borne and Zoonotic evidence from a wildlife epizootic in West Texas 2010', Vector-B
Diseases 14, 576-583. https://doi.org/10.1089/vbz.2013.1538

Braack, L.E.O., 1985, 'An ecological investigation of the insects associated with exposed carcasses in the northern Kruger National Park: A study of populations and communities', PhD thesis, Department of Entomology, University of Natal, South Africa.

Braack, L.E.O. \& De Vos, V., 1990, 'Feeding habits and flight range of blow-flies (Chrysomyia spp.) in relation to anthrax transmission in the Kruger National Park, South Africa', The Onderstepoort Journal of Veterinary Research 57, 141-142.

Braack, L.E.O. \& Retief, P.F., 1986, 'Dispersal, density and habitat preference of the blow-flies Chrysomya albiceps (Wd.) and Chrysomya marginalis (Wd.) (Diptera: Calliphoridae)', The Onderstepoort Journal of Veterinary Research 53, 13-18.

De Vos, V., 1990, 'The ecology of anthrax in the Kruger National Park, South Africa', Salisbury Medical Bulletin 68S, 19-23.

De Vos, V., 1994, 'Anthrax', in J.A.W. Coetzer, G.R. Thomson \& R.C. Tustin (eds.), Infectious diseases of Livestock with special reference to Southern Africa, pp. 1262-1289, Vol. 2, Oxford University Press, Cape Town, South Africa.

Dragon, D.C. \& Rennie, R.P. 1995, 'The ecology of anthrax spores: Tough but not invincible', The Canadian Veterinary Journal 36, 295-301.

Eloff, J.N., 1998, 'A sensitive and quick microplate method to determine the minimal inhibitory concentration of plant extracts for bacteria', Planta Medica 64 711-713. https://doi.org/10.1055/s-2006-957563

Fasanella, A., Scasciamacchia, S., Garofolo, G., Giangaspero, A., Tarsitano, E. \& Adone, R., 2010, 'Evaluation of the house fly Musca domestica as a mechanical vector for an anthrax', PLoS One 5, 1-5. https://doi.org/10.1371/journal.pone.0012219

Furstenburg, D., 2002, Impala 'Rooibok' Aepyceros melampus, viewed 24 November 2010, from http://gadi.agric.za/articles/Furstenburg_D/impala.php

Graham-Smith, G.S., 1913, Flies and disease: Non-bloodsucking flies, Cambridge University Press, London.

Haines, R.B., 1938, 'The effect of freezing on bacteria', Proceedings of the Royal Society B: Biological Sciences 124, 451-463. https://doi.org/10.1098/rspb.1938.0005

Hugh-Jones, M.E. \& Blackburn, J.K., 2009, 'The ecology of Bacillus anthracis', Molecular Aspects of Medicine 30, 356-367. https://doi.org/10.1016/j.mam.2009.08.003

Hugh-Jones, M.E. \& De Vos, V., 2002, 'Anthrax and wildlife', Revue Scientifique Et Technique (International Office des Epizootics) 21, 359-383. https://doi.org/ 10.20506/rst.21.2.1336

Koekemoer, L.L., Kamau, L., Hunt, R.H. \& Coetzee, M., 2002, 'A cocktail polymerase chain reaction assay to identify members of the Anopheles funestus (Diptera: Culicidae) group', American Journal of Tropical Medicine and Hygiene 6, 804-811. https://doi.org/10.4269/ajtmh.2002.66.804

Pienaar, U., de V., 1961, 'A second outbreak of anthrax amongst game animals in the Kruger National Park 5th June to 11th October 1960', Koedoe 4, 4-14. https://doi. org/10.4102/koedoe.v4i1.824

Pienaar, U., de V., 1967, 'Epidemiology of anthrax in wild animals and the control of anthrax epizootics in the Kruger National Park, South Africa', Federation Proceedings 26, 1496-1502.

Turell, M.J. \& Knudson, G.B., 1987, 'Mechanical transmission of Bacillus anthracis by stable flies (Stomoxys calcitrans) and mosquitoes (Aedes aegypti and Aedes taeniorhynchus)', Infection and Immunity 55, 1859-1861.

Turner, W.C., Kausrud, K.L., Beyer, W., Easterday, W.R., Barandongo, Z.R., Blaschke, E. et al., 2016, 'Lethal exposure: An integrated approach to pathogen transmission via environmental reservoirs', Scientific Reports 6, 27311. https://doi.org/10.1038/ srep 27311

Turner, W.C., Kausrud, K.L., Krishnappa, Y.S., Cromsigt, J.P.G.M., Ganz, H. H., Mapaure, I. et al., 2014, 'Fatal attraction: Vegetation responses to nutrient inputs attract herbivores to infectious anthrax carcass sites', Proceedings of the Royal Society of London Series B: Biological Sciences 281, 20141785. https://doi.org/10.1098/rspb.2014.1785

Von Terzi, B., Turnbull, P.C.B., Bellan, S.E. \& Beyer, W., 2014, 'Failure of Sterne- and Pasteur-like strains of Bacillus anthracis to replicate and survive in the urban Pasteur-like strains of Bacillus anthracis to replicate and survive in the urban
bluebottle blow fly Calliphora vicina under laboratory conditions', PLoS One 9 , 1-7. https://doi.org/10.1371/journal.pone.0083860
(l)

World Health Organization, 2008, Anthrax in humans and animals, 4th edn., WHO press, Geneva.

Young, R.S., Deal, P.H. \& Whitfield, O., 1968, 'The response of spore-forming vs. nonspore-forming bacteria to diurnal freezing and thawing', Origins of Life and Evolution of Biospheres 1, 113-117. https://doi.org/10.1007/BF00924233

Zumpt, F., 1965, Myiasis in man and animals in the old world, Butterworths, London. 


\section{Appendix 1}

TABLE 1-A1: Presence and number of colony forming units of Bacillus anthracis on and/or in blowflies collected from the confirmed anthrax-positive kudu carcass (2-3 day old) during anthrax outbreak in Kruger National Park in 2014.

\begin{tabular}{|c|c|c|c|c|c|}
\hline Species name & Sex & External or internal positive & $\begin{array}{l}\text { Vegetative cells or spores } \\
\text { detected }\end{array}$ & External counts (CFU/fly) & Internal counts (CFU/fly) \\
\hline Ch. albiceps & Female & Internal & Spores & 0 & 20 \\
\hline Ch. marginalis & Male & Internal & Spores & 0 & 10 \\
\hline Ch. marginalis & Female & External & Spores & 10 & 0 \\
\hline Ch. marginalis & Female & Both & Spores & 20 & 20 \\
\hline Ch. marginalis & Female & Both & Spores & 200 & 10 \\
\hline Ch. marginalis & Female & Both & Spores & 20 & 90 \\
\hline Ch. marginalis & Female & Both & Spores & 550 & 280 \\
\hline Ch. marginalis & Male & Both & Spores & 90 & 100 \\
\hline Ch. marginalis & Female & Both & Spores & 40 & 20 \\
\hline Ch. marginalis & Female & Both & Spores & 60 & 100 \\
\hline Ch. marginalis & Female & Both & Spores & 50 & 40 \\
\hline Ch. marginalis & Female & Both & Spores & 10 & 10 \\
\hline Ch. marginalis & Female & External & Spores & 10 & 0 \\
\hline Ch. marginalis & Female & Both & Spores & 20 & 10 \\
\hline Lucilia spp. & Female & External & Spores & 10 & 0 \\
\hline Lucilia spp. & Female & External & Spores & 10 & 0 \\
\hline
\end{tabular}

CFU, colony forming units per fly.

\section{Appendix 2}

TABLE 1-A2: Presence and number of colony forming units of Bacillus anthracis on and/or in blowflies collected from the confirmed anthrax-positive impala carcass (2-3 days old) during anthrax outbreak in Kruger National Park in 2014.

\begin{tabular}{|c|c|c|c|c|c|}
\hline Species name & Sex & External or internal positive & Vegetative cells or spores detected & External counts (CFU/fly) & Internal counts (CFU/fly) \\
\hline Ch. marginalis & Female & Internal & Spores & 0 & 30 \\
\hline Ch. marginalis & Male & Internal & Spores & 0 & 10 \\
\hline Ch. marginalis & Female & External & Spores & 30 & 0 \\
\hline Ch. marginalis & Male & Internal & Spores & 0 & 20 \\
\hline Ch. marginalis & Male & External & Spores & 20 & 0 \\
\hline Ch. marginalis & Male & Internal & Spores & 0 & 50 \\
\hline Ch. marginalis & Male & Internal & Spores & 0 & 20 \\
\hline
\end{tabular}

CFU, colony forming units per fly. 